DOI 10.37882/2223-2974.2020.11.15

\title{
АДМИНИСТРАТИВНО-ПРАВОВЫЕ ПРИНЦИПЫ ЧЕРЕЗ ПРИЗМУ ФЕНОМЕНОЛОГИИ ПРАВА
}

\section{ADMINISTRATIVE AND LEGAL PRINCIPLES THROUGH THE PRISM OF THE PHENOMENOLOGY OF LAW}

O. Karpov N. Kuchin

Summary: Currently, the methodology of administrative law is quite developed, both in the structural ordering of the balance of all elements that make up the theoretical system of the science of administrative law, and in the practice-oriented paradigm aimed at solving certain problems in the organization of managerial relations, and establishing the administrative and legal status of the subject of these relations. This article examines administrative and legal principles through the prism of the phenomenology of law, as the science of studying various legal phenomena, their relationships and patterns in practical application, and the interaction of various social groups in society. The authors also analyze the administrative and legal model in society from the point of view of studying the legal phenomena that are part of its structure, in order to identify patterns that make it possible to put into practice the theoretical aspects of administrative and legal science, in particular:

Keywords: methodology, theoretical system, administrative law, managerial relations, administrative and legal principles, society, administrative and legal model, legal regularities, legal matter, legal norms, legal relations, administrative proceedings.

\author{
Карпов Олег Вячеславович \\ старший преподаватель, Владимирский \\ филиал РАНХиГС, г. Владимир \\ okarp67@mail.ru \\ Кучин Никита Сергеевич \\ Владимирский филиал РАНХиГС, г. Владимир \\ nik.antipov.2000@inbox.ru
}

Аннотация: В настоящее время методология административного права является достаточно разработанной, как В структурном упорядочивании баланса всех элементов, составляющих теоретическую систему науки административного права, так и в практико-ориентированной парадигме, направленной на решение определенных задач в сфере организации управленческих отношений, и установлении административно-правового статуса субъекта этих отношений. В настоящей статье исследуются административно-правовые принципы через призму феноменологии права, как науки об изучении различных правовых феноменов, их взаимосвязей и закономерностей при практическом применении, и взаимодействии различных социальных групп в обществе. Также авторами анализируется административно-правовая модель в социуме с позиции изучения правовых феноменов, входящих в ее структуру, с целью выявления закономерностей, позволяющих воплотить на практике теоретические аспекты административно-правовой науки, в частности увидеть процесс «транспортировки» теоретически изученных принципов административного права в практическую правовую материю, нормы права, а также исследовать влияние основополагающих понятий на правоотношения объекта и субъекта управления в рамках конкретного административного производства.

Ключевые слова: методология, теоретическая система, административное право, управленческие отношения, административно-правовые принципы, социум, административно-правовая модель, правовые закономерности, правовая материя, нормы права, правоотношения, административное производство.

циальной повседневности, в «жизненном мире» людей и для каждого конкретного индивида.

нистративное право применяет отечественный философ и методолог права, Н.Н. Алексеев. Он раскрывает правовые феномены через призму феноменологических установок, анализирует правовое поведение, институт административного управления, а также предпринимает попытки создания феноменологической административно- правовой методологии [3]. Философ рассматривает социальный мир правовой повседневности людей с разных позиций, как позиций субъекта управления, так и с позиции «управленца», наблюдателя за поведением субъекта управления. Многосторонний подход к изучению феномена «административное право» позволяет раскрыть его многоаспектность. Изучение через наложение разных парадигм способно дать виденье административного права таким, каким оно является в мире со-

На практике феноменология показывает каким образом у субъекта управления происходит формирование мотивационного поведения в сознании, иначе говоря, каким образом человек принимает решение исполнять или не исполнять то или иное указание, закон, распоряжение. К примеру, с помощью феноменологической процедуры редукции на практике можно определить степень коррупционной составляющей в поведении субъекта, находящегося на определенной должности, проследить уровень мотивации исполнения им своих обязанностей. Данная процедура позволяет также сформировать методику понимания индивидуального правосознания отдельно взятого субъекта, что, несомненно, может помочь законодателю, учитывающему отношение 
граждан и государственных служащих к будущему закону.

Любая юридическая теория не может дать объективного представления о правовой действительности. Она лишь обобщает некие признаки, через которые, в частности, социальная феноменология и раскрывает новый подход, отличный от естественного и позитивного подхода к «право-пониманию». Напротив, применение феноменологических методов познания к описанию жизни индивидов в мире административно-правовых отношений позволяет нам говорить о интегративном подходе, целью которого является построение методологической основы, неклассической науки о жизни субъекта в «мире правового управления». Уникальность применения феноменологии к административному праву позволяет решить некоторые проблемы старой классической правовой методологии, в частности создать единое «конституирование» - понимание правовых смыслов, заложенных в нормы законов; изучить процессы, протекающие в реальном «жизненном мире» людей, находящихся в административно-правовых отношениях.

Административное право - одна из центральных и базовых отраслей, правовой системы Российской Федерации, а правовые нормы, закрепленные в законодательстве, служат нормативной правовой основой построения и функционирования самой обширной и многочисленной ветви власти - исполнительной. Административное право относится к отрасли публичного права, права общегосударственного интереса: в частности, закрепляет права и обязанности граждан и юридических лиц, не обладающих властными полномочиями, регулирует и стабилизирует отношения вышеизложенных субъектов с представителями исполнительной власти, как на федеральном, так и на региональном уровне, а также органами местного самоуправления. Административное право, в основе которого лежит функция управления, определяет структуру, сбалансированную систему, принципы, а также различные методы и формы деятельности исполнительных органов, лиц, находящихся на государственной службе [4, с. 75]. Изучение принципов административного права является важнейшей составляющей, так как они являются основополагающими началами, объединяющими и систематизирующими остальные элементы административно-правовой науки. В любой науке, деятельности, принципы являются «фундаментом», на котором строится, как практическая, так и теоретическая система научного или иного человеческого знания.

На наш взгляд, применение к исследованию административно-правовых принципов феноменологии права, ее методов и инструментов познания поможет более системно понять заложенный в этих принципах смысл. Рассматривая принцип через призму феномена, можно увидеть не только сокрытый в нем теоретический по- тенциал, но также проследить закономерную связь с его практическими трансформациями в правовую материю социума, понять каким же образом он влияет на те или иные правовые отношения.

Принципы административного права - один из элементов механизма административно-правового регулирования, но на наш взгляд, это базовый элемент, так как, именно он наиболее сильно влияет на управленческие отношения, учитывая потребности общества и государства. По мнению Д.Н. Бахраха, под административноправовыми принципами следует понимать основополагающие начала, охарактеризовавшие его смысловое содержание, определяющие закономерности развития и фиксирующие механизм административно-правового регулирования отношений, построенных на парадигме управления [4, с. 113]. Проводя теоретическое исследование административно-правовых принципов, можно выделить характерные, объединяющие и присущие всем принципам основные черты:

- определяют юридическую силу административного права;

- обусловлены развитием общества, качеством правосознания и правовой культуры;

- являются «мостиком» между теоретической наукой и практическими правовыми реалиями ее существования;

- формируются под непосредственным влиянием теории права, учитывая взгляды ученых, теоретиков, юристов на процессы правового регулирования государственного управления.

В административно-правовой науке существует определенное разделение принципов. В частности, С.С. Алексеев различает общие принципы права, отраслевые принципы и правовые аксиомы. Общие принципы, по его мнению, включают в свое содержание социально-экономические, политические, идеологические, политико-национальные и нравственные начала. Из их содержания ученый выделяет общие правовые принципы: законности, справедливости, юридического равенства, социального и гражданского долга, объективной истины, ответственности за вину. Отраслевые принципы делятся на общие отраслевые, межотраслевые и специфические отраслевые. Правовыми аксиомами характеризуются положения, которые имеют для права значение непреложных истин (например, нельзя осуждать дважды за одно и то же правонарушение).

К основным принципам административного права относят: принцип равенства лиц перед законом, нормативно закрепленном в ст. 1.4 КоАП РФ[2]. Не стоит путать его с похожим принципом равенства в гражданском праве, где стороны равны не только перед законом, но и между собой при вступлении в договорные отношения. В отличии от гражданского права административное построено на неравенстве сторон, вступающих в отношения. 
Это обусловлено функциями управления и подчинения, заложенными в специфику данной отрасли. Принцип разделения властей определяет самостоятельность исполнительной власти в пределах, закрепленных Основным законом Российской Федерации. На наш взгляд, основная задача исполнительной власти - это грамотная и своевременная реализация законов и иных нормативных правовых актах на практике. Принцип приоритетности интересов отдельной личности в жизни общества является одним из базовых. Это подтверждается 2 статьей Конституции Российской Федерации, провозглашающей права и свободы человека высшей ценностью, и закрепляющей обязанность государства признавать и охранять их [1]. Принцип законности декларирует, что все правовые акты, принятые на территории Российской Федерации, не должны противоречить Основному закону страны, тем самым обязывая исполнительную власть на всех уровнях соблюдать законность принятых актов. Презумпция невиновности - один из межотраслевых принципов в административном праве получил закрепление в ст. 1.5, п.2 КоАП РФ, данный принцип можно представить в виде формулы «невиновен, пока не доказано обратное» [2].

Рассматривая вышеизложенные принципы с точки зрения феноменологии права, можно проследить процесс их появления и практической трансформации. Принципы любой отрасли права, берут свое начало из моральных заветов и догм, впоследствии трансформируясь в философско-правовые ценности, из которых, согласно определенной специфике, становятся основополагающими началами права. Феноменология необходима в изучении административно-правовых феноменов. Правовые принципы, и вообще ценности и принципы социума выводятся за бытие человека в трансцендентальную зону высших монад, как говорил Э. Гуссерль, откуда наблюдатель берет их и транспортирует в рамки своего сознания, а далее и повседневного мира. Философия права, применяя методы социальной феноменологии, исследует процесс транспортирования правовых норм в социальный мир повседневности. Мир права, это отдельный вид мира социального, где индивиды находятся в некой «нормативной» зависимости друг от друга, и чем фундаментальнее правовые принципы и значимость их стабильности, тем лучше происходит транспортирование правовых принципов, как абстрактных, трансцендентальных сущностей в бытие реальных правовых взаимоотношений людей.

Таким образом, вышесказанное позволяет говорить о принципах административного права именно как об основном элементе системы административно-правовой науки, как в теоретическом плане, так и в практической парадигме. Ярким примером этому может служить закрепление целого ряда принципов в Основном законе нашего государства.
Рассмотрев общетеоретические моменты связанные с феноменологией права и появлением принципов в правовой жизни индивидов, нам хотелось бы перейти, к вопросу о значимости и конкретным практическим моментам, где административно - правовые принципы трансформировались в определенные нормы административного права и правовое поведение субъектов. На наш взгляд, именно в административном производстве, нашли современную интерпретацию феноменологически исследованные принципы административного права. Правовой основой реализации производства по делам об административных правонарушениях являются его принципы, руководящие идеи, общественные представления о реализации такого производства. По мнению В. А. Иванцова, в научно-правовой литературе к принципам административного производства относят принципы: законности; публичности; независимость субъектов юрисдикции, принимающих решения; осуществления административного процесса на национальном языке. Принцип охраны интересов государства и личности не нашел своего отображения в административно-деликтном законодательстве, но логически вытекает из систематического толкования его норм. В отличии от преступлений административные правонарушения отличаются общественной вредностью, которая в большинстве случаев не имеет материальной формы. Принцип сочетания диспозитивности и императивности в последнее время становиться все более актуальным. Дело в том, что в связи с прогрессом общества и изменением характера правоотношений в различных сферах публичного администрирования, наряду с присущим для административного права императивным методом, лишающим права выбора, все чаще применяется диспозитивный метод, позволяющий субъекту право выбирать вариант поведения в зависимости от специфики личных предпочтений. И административно-деликтная сфера - яркий пример тому в подтверждение.

Содержание производства по делам об административных правонарушениях обусловлено его задачами и целями, а принципы содержат концептуальные парадигмы для его осуществления, основные правила, которые должны систематически и неуклонно выполнятся во время непосредственного применения. Понимание практической сущности административно-правовых принципов позволит наиболее эффективно реализовать заложенный в них потенциал. Поэтому на наш взгляд, перспективным направлением дальнейшего исследования является переосмысление принципов, заложенных, как в административное производство, так и в науку административного права, исходя из «новелизации» законодательства, что на практике отразится в большем качестве итоговых решений и в целом позитивно скажется на «сближении» административно-правового законодательства и специфики реальной жизни общества.

На практики данные положения могут реализоваться 
прежде всего в нормативных правовых актах, издаваемых органами государственной власти, где акцент будет делаться на воплощение сути принципов в реальную повседневную жизнь, через внешнее закрепление - в виде правовой нормы, следуя правилу «форма закона, пропитанная духом права», что несомненно положительно скажется на отношениях «гражданин-государство», ведь принципы отражают суть права, а значит несут в себе и моральные аспекты, намного «ближе» воспринимаемые человеком, чем формально-декларированные правила поведения.

Рассматривая административно-правовую модель через призму феноменологии права, можно увидеть каким образом происходят процессы административного регулирования, управления и построения правоотношений между субъектами в реальном «жизненном» мире людей. Административное право, являясь абстрактным, трансцендентальным набором правовых институтов и феноменов, на практике находит свое выражение, как социальный регулятор общественных отношений обладающих определенной спецификой, в основе которой, как раз и находятся административно-правовые принципы. Применяя методы феноменологии к изучению феноменов и институтов, составляющих науку административного права, возможно изучить их с позиции теории и мнений ученых, теоретиков и юристов, а также что немаловажно, проанализировать каким образом они «вплетаются» В реальную правовую материю. К примеру, новый для российского законодательства принцип эстоппельозначающий запрет противоречивого и непоследовательного поведения, при условии, что такое поведение создает явную несправедливость, но не блокирует полностью непоследовательность поведения как токовую, а лишь предотвращает подрыв доверия одной стороны у другой, когда несправедливость достигает определенного уровня. Как мы видим в теории отечественного права термин достаточно разработан и детализирован, хотя «родиной» эстоппеля является английское договорное право. Изучив данный феномен с теоретических позиций, феноменология права предлагает нам практическую модель в котором данный принцип реализуется. К примеру: у одной стороны есть некое, формальное право, но ее поведение дает основания разумно полагать, другой стороне, что она этим правом пользоваться не будет, но в дальнейшим обладая формальным правом сторона начинает резко менять позицию на диаметрально-противоположную, настаивая на своем праве, тем самым создавая другой стороне ущерб. В этом случаи орган, рассматривающий дело, видя, что «порог несправедливости» пройден, начинает применять принцип эстоппеля [5].

Как мы видим, феномен «эстоппеля» -являясь «чистым» воплощением принципа добросовестности нашел свое практическое применение в судебной практике, как по административным спорам, так и по гражданскоправовым, что говорит об универсальности, всеобщности принципа, в данном случае связывающего публичноправовую и частноправовую отрасль права.

Таким образом, подводя итог вышесказанному, мы делаем вывод о необходимости применения феноменологии права в изучении феноменов, институтов и закономерностей административно-правовой науки. Исследованные через феноменологическую призму термины и понятия позволяют как обогатить методологию административно-правовой науки, так и увидеть их особое понимание каждым конкретным индивидом. В данном исследовании нами анализировались принципы административного права, как основополагающие начала, лежащие в основании всех его институтов. Административно - правовая модель, построенная на балансе теоретических принципов и реальной практики их применения, позволяет сохранить стабильность в правоотношениях и процессах государственного управления $[6$, c.14].

Кроме этого, хотелось бы также отметить, что практическая значимость исследуемой нами проблематики, прежде всего заключается в новом осмыслении связи теории и практики административного права. В данном случае таким «мостиком» является феноменология права, как наука, занимающаяся отношением, переживанием, пониманием субъектом права тех событий, которые происходят с ним в повседневной правовой жизни. Административно-правовые принципы выступают основными элементами в административно-правовой модели, где акцент делается на субъект права, как главного участника отношений. По сравнению с классической правовой теорией, где «ядром» является государство, это позволяет по-новому взглянуть на значимость и необходимость обществу административного права, на практике позволяющего подчеркивать, как значимость государства, так и значимость отдельного взятого его гражданина.

\section{ЛИТЕРАТУРА}

1. Конституция Российской Федерации (принята всенародным голосованием 12.12.1993) (с учетом поправок, внесенных Законами РФ о поправках к Конституции РФ от 30.12.2008 № 6-ФКЗ, от 30.12.2008 № 7-ФК3, от 05.02.2014 № 2-ФК3, от 21.07.2014 № 11-ФКЗ, от 14.03.2020 № 1-ФК3) // Российская газета, № 144,8. 
2. Кодекс Российской Федерации об административных правонарушениях: Федеральный закон Российской Федерации от 30.12.2001 № 195-Ф3 (ред. от 01.04.2020) // Российская газета, № 256, 31.12.2001.

3. A Dictionary of Law. Fifth Edition. Reissued with new covers / ed. by E. A. Martin. - 0xford, 2003.- 1627 p.

4. Бахрах Д.Н., Российский Б.В., Старилов Ю.Н. Административное право: Учебник для вузов. — 2-е изд., изм. и доп. — М. Норма, 2005.

5. Дружинин, А. Принцип «эстоппель» в действии: когда участник спора может лишиться права выдвигать возражения / А. Дружинин // Ваш партнер-консультант». - 2015 - № 20 (9586). [Электронный ресурс] - URL: https://www.eg-online.ru/article/282067/.

6. Иванцов В.А. К вопросу о современной интерпретации принципов административного права при рассмотрении дел об административных правонарушениях // «Colloquium-journal» № 22 (46), 2019. ( 14-16.

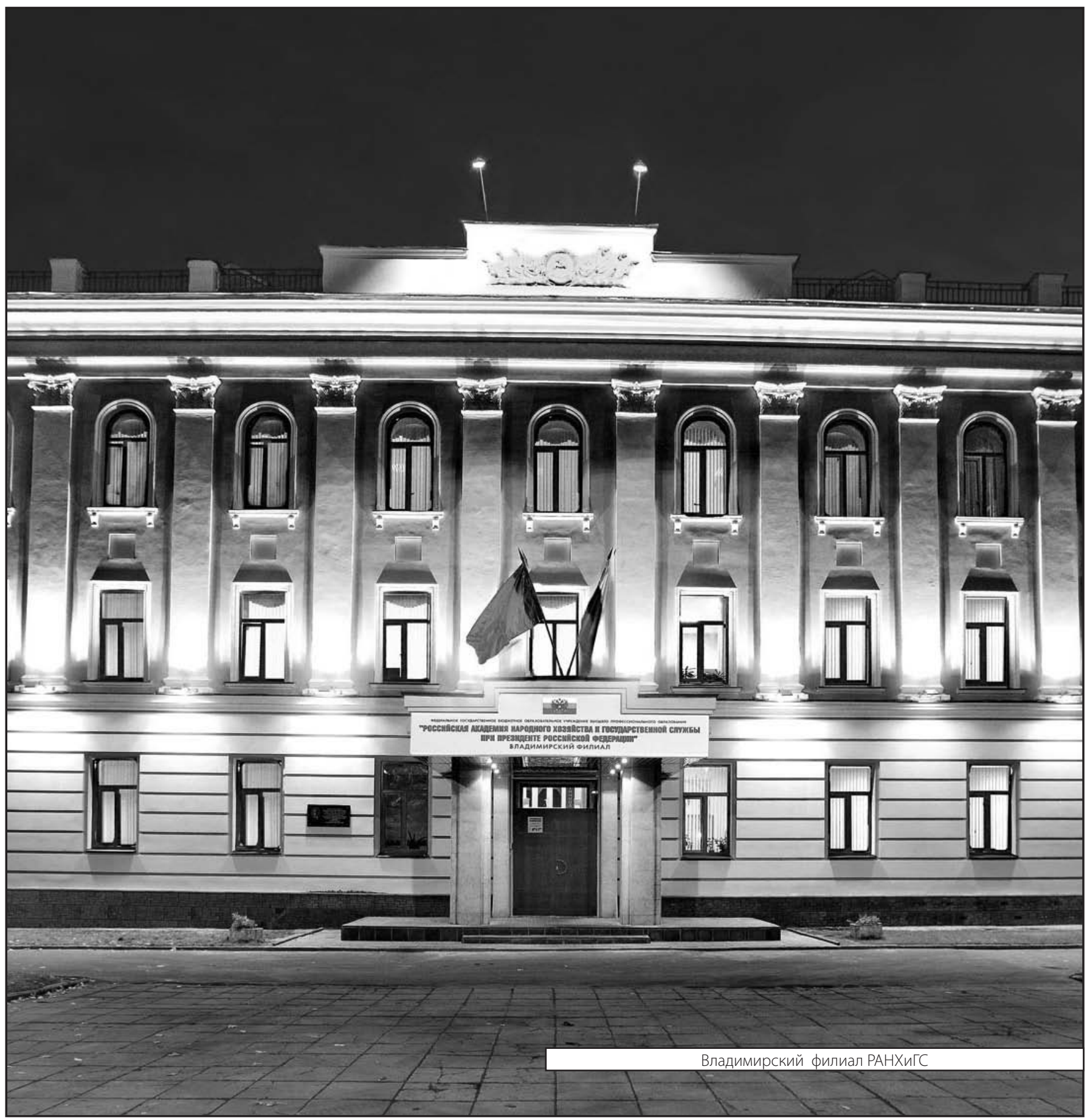

